\title{
In silico identification of putative promoter motifs of White Spot Syndrome Virus \\ Hendrik Marks ${ }^{1,3}$, Xin-Ying Ren², Hans Sandbrink², Mariëlle CW van Hulten $^{1,4}$ and Just M Vlak*1
}

Address: ${ }^{1}$ Laboratory of Virology, Wageningen University, Binnenhaven 11, 6709 PD Wageningen, The Netherlands, ${ }^{2}$ Plant Research International, Postbus 16, 6700 AA, Wageningen, The Netherlands, ${ }^{3}$ NCMLS/Radboud University Nijmegen, Department of Molecular Biology, Geert Grooteplein 26/28, 6525 GA, Nijmegen, The Netherlands and ${ }^{4}$ CSIRO Livestock Industries, 306 Carmody Road, St Lucia 4067, Brisbane, Australia

Email: Hendrik Marks - hendrikmarks@hotmail.com; Xin-Ying Ren - xinying.ren@wur.nl; Mariëlle CW van Hulten - mariellevh@hotmail.com; Just M Vlak* - just.vlak@wur.nl

* Corresponding author

Published: 19 June 2006

BMC Bioinformatics 2006, 7:309 doi:10.1 |86//47|-2105-7-309
Received: 12 February 2006

Accepted: 19 June 2006

This article is available from: http://www.biomedcentral.com/I47I-2105/7/309

(c) 2006 Marks et al; licensee BioMed Central Ltd.

This is an Open Access article distributed under the terms of the Creative Commons Attribution License (http://creativecommons.org/licenses/by/2.0), which permits unrestricted use, distribution, and reproduction in any medium, provided the original work is properly cited.

\begin{abstract}
Background: White Spot Syndrome Virus, a member of the virus family Nimaviridae, is a large dsDNA virus infecting shrimp and other crustacean species. Although limited information is available on the mode of transcription, previous data suggest that WSSV gene expression occurs in a coordinated and cascaded fashion. To search in silico for conserved promoter motifs (i) the abundance of all 4 through 8 nucleotide motifs in the upstream sequences of WSSV genes relative to the complete genome was determined, and (ii) a MEME search was performed in the upstream sequences of either early or late WSSV genes, as assigned by microarray analysis. Both methods were validated by alignments of empirically determined 5 ' ends of various WSSV mRNAs.

Results: The collective information shows that the upstream region of early WSSV genes, containing a TATA box and an initiator, is similar to Drosophila RNA polymerase II core promoter sequences, suggesting utilization of the cellular transcription machinery for generating early transcripts. The alignment of the 5 ' ends of known well-established late genes, including all major structural protein genes, identified a degenerate motif (ATNAC) which could be involved in WSSV late transcription. For these genes, only one contained a functional TATA box. However, almost half of the WSSV late genes, as previously assigned by microarray analysis, did contain a TATA box in their upstream region.

Conclusion: The data may suggest the presence of two separate classes of late WSSV genes, one exploiting the cellular RNA polymerase II system for mRNA synthesis and the other generating messengers by a new virus-induced transcription mechanism.
\end{abstract}

\section{Background}

White Spot Syndrome Virus (WSSV), type species of the virus family Nimaviridae (genus whispovirus), is a pathogen of major economic importance in cultured penaeid shrimp [1,2]. Histopathological studies on WSSV infected shrimp have shown that the virus mainly infects tissues of ectodermal and mesodermal origin, such as the stomach, gills, heart, gut, muscle tissue and hematopoietic tissue [35]. Infected cells within these tissues are characterized by the appearance of homogeneous hypertrophied nuclei 
and chromatin margination $[1,5,6]$. WSSV particles have been mainly detected in the nuclei of infected cells, indicating that transcription, replication and virion assembly probably occur in the nucleus [5-8]. It is not clear how the virions are released from the nucleus of an infected cell, but this most likely occurs by budding or by rupture of the nuclear envelope and/or the cell membrane.

The circular ds DNA genome of three WSSV isolates, originating from Taiwan (WSSV-TW), China (WSSV-CN) and Thailand (WSSV-TH), have been completely sequenced [9-11]. The genome of WSSV-TH has a size of 292,967 bp encompassing 184 open reading frames (ORFs), which are almost equally distributed on both strands [10]. Thus far, no evidence has been obtained for the occurrence of spliced transcripts. Only a limited amount of the WSSV ORFs could be assigned a function based on homology with known genes in public databases [10]. Concerning genes involved in replication and transcription of WSSV, four putative functional proteins have been annotated: a DNA helicase (ORF9), a DNA polymerase (ORF27), a cAMP-responsive element binding protein (ORF66) and a TATA box binding protein (ORF149). Furthermore, several genes involved in nucleotide metabolism, such as both subunits of a ribonucleotide reductase, a chimeric thymidine-thymidylate kinase, a thymidylate synthase, a dUTPase and an endonuclease have been identified on the genome $[10,11]$. Although present in various other large dsDNA viruses, no RNA polymerase or other genes involved in transcription, e.g. a poly(A)polymerase or mRNA capping enzymes, have (yet) been identified on the WSSV genome. Around 50 major or minor virion protein genes have been identified on the genome [12-15].

Upon infection, expression of the WSSV genes can be divided in at least an early and a late phase [16], while also an immediate-early phase might be present [17]. The mechanism of the switch between (immediate-) early and late WSSV gene expression, as well as the promoters and regulatory sequences involved, is largely unknown. However, many eukaryotic large ds DNA viruses of $>100 \mathrm{~kb}$ have a coordinated and cascaded fashion of gene expression [18-21]. Baculoviruses and herpesviruses (both replicating in the nucleus) as well as poxviruses and asfarviruses (both replicating in the cytoplasm) express their early genes before viral replication initiates, while late genes are expressed after the onset of viral DNA replication. Both viruses replicating in the nucleus utilize the host RNA polymerase II for early gene transcription $[19,22]$. However, for late gene transcription, herpesviruses continue to exploit the cellular RNA polymerase II system, while late transcription of baculoviruses occurs by a novel RNA polymerase that is at least partially encoded by the baculovirus genome [22-24]. The viruses replicating in the cytoplasm encode their own RNA polymerase which synthesizes early as well as late mRNAs. This RNA polymerase is encapsidated within the virus particle to enable the initiation of viral gene expression upon arrival in the cytoplasm $[18,25]$.

Despite the differences in gene expression strategies, the above viruses have in common that specific nucleotide motifs involved in transcription initiation, expression kinetics and expression level have been identified in the upstream regions of individual genes. Well known promoter elements used by many viruses are the TATA box and the initiator sequence, which is located at or near the site of transcription initiation (TIS). We hypothesize that conserved promoter motifs play an important role in transcription regulation of WSSV, and that they can be identified by in silico analysis of upstream regions of WSSV genes. As important promoter motifs are overrepresented in the 5' upstream regions of baculoviruses genes [26], we studied the relative abundance of all 4 through 8 nucleotide motifs in the upstream regions of WSSV genes compared to the complete WSSV genomic sequence. This enumeration strategy was validated by testing the eukaryotic large ds DNA viruses mentioned above. To further identify regulatory elements, the nucleotide composition in the upstream regions of WSSV early and late genes, as assigned by microarrays [16], is studied using MEME [27]. MEME is an algorithm which searches for conserved motifs in a selected set of sequences, in this case the upstream regions of WSSV ORFs. Experimental support for the in silico results is obtained by alignments of $5^{\prime}$ ends of known WSSV early as well as late transcripts. These alignments include TISs mapped by 5'RACE (Rapid Amplification of cDNA Ends) in previous studies, as well as two newly determined TISs of the major structural protein genes ORF112 and ORF160. Polyadenylation of WSSV early and late genes is studied by alignment of poly(A) sites. Using this approach, we were able to find further support for the presence of coregulated clusters of WSSV genes, as well as to predict putative WSSV promoter elements involved in gene expression of these clusters.

\section{Results \\ Promoter analysis using the enumeration method}

In a search for putative WSSV regulatory promoter elements, we compared the abundance of all 4, 5, 6, 7 or 8 nucleotide motifs in the 100 and $200 \mathrm{nt}$ upstream sequences of all WSSV genes relative to their presence in the complete WSSV genomic sequence. This method will be referred to as the enumeration method in the remaining part of the article. For validation, this enumeration method was applied on the genome sequences of the type species of more extensively studied large ds DNA viruses mentioned in the introduction: AcMNPV (Autographa californica Multinucleopolyhedrovirus; Baculovirus), Human Herpes Virus 1 (HHV1; Herpesvirus), Vaccinia 
virus (Poxvirus) and African Swine Fever Virus (ASFV; Asfarvirus).

\section{AcMNPV, HHVI, Vaccinia virus and ASFV}

Only the analysis of the 4-mers of these viruses is shown, as these will always be included in larger motifs (Table 1). Most AcMNPV early genes contain a functional consensus TATA box upstream of the TIS [19]. AcMNPV initiator motifs are composed of the conserved nucleotide sequence CAGT and $(\mathrm{a} / \mathrm{g} / \mathrm{t}) \mathrm{TAAG}$, for early and late genes, respectively $[18,23,28]$. Ayres $e t$ al. [26] showed that the sequence TAAG occurs less frequently in the whole AcMNPV genome than expected based of the AcMNPV nucleotide composition. The results of the 4-mer motif frequency in the $100 \mathrm{nt}$ upstream of all AcMNPV ORFs analyzed with the enumeration method indeed shows that the TAAG motif frequency is $29 \%$ of the expected occurrence in the whole genome (Table 1). However, the analysis also shows that this motif has the highest relative enrichment in the upstream regions of the AcMNPV ORFs of all possible 4-mer motifs (4.0 times). Also the baculovirus early promoter motif CAGT is relatively more frequently present in upstream regions (1.4 times), although not as prominent as the TAAG motif. Parts of the TATA box as well as sequences of the well known baculovirus early transcription activating motifs GATA and CACNG [19] occur relatively often in the upstream regions of the ORFs (Table 1). Compared to $100 \mathrm{nt}$, the enrichment of the functional motifs in $200 \mathrm{nt}$ upstream of the AcMNPV ORFs is less pronounced (Table 1) supporting the experimental observation that in baculoviruses important promoter elements are often located within $100 \mathrm{nt}$ upstream of the translational start codon [26]. Analysis of 5-mer motifs of AcMNPV revealed that $(\mathrm{a} / \mathrm{g} / \mathrm{t}) \mathrm{TAAG}$ was enriched in the upstream regions of the ORFs, but not CTAAG. Analysis of 6-mer motifs showed a relative enrichment of 3.0 times of the consensus TATA box sequence TATAAA in the $200 \mathrm{nt}$ upstream regions.

For HHV1, the 4-mer nucleotide motifs of known promoter elements were identified by the enumeration method during analysis of the $200 \mathrm{nt}$ upstream sequences, but not when analyzing $100 \mathrm{nt}$ upstream sequences. This supports the view that, in contrast to baculoviruses, most regulatory elements are located more than $100 \mathrm{nt}$ upstream of the HHV1 translational start codons [21]. Parts of the consensus TATA box, involved in HHV1 early and late transcription $[21,29]$, occur relatively frequently in the $200 \mathrm{nt}$ upstream of the HHV1 ORFs (Table 1). Also the sequence CATT, part of the CCATT boxes which are typically located upstream of the consensus TATA box of HHV1 early genes [21], shows a high relative enrichment of 2.1 (Table 1).
For both cytoplasmatic viruses Vaccinia virus and ASFV the analysis shows that the late initiator sequences, TAAAT and TATA respectively $[18,20,30]$, are highly enriched in the $100 \mathrm{nt}$ as well as the $200 \mathrm{nt}$ upstream sequences, although not as prominent as the late TIS of baculoviruses (Table 1). Also parts of the sequence TAAA $(\mathrm{a} / \mathrm{t})$, essential for Vaccinia virus intermediate gene expression, are enriched (Table 1). Furthermore, the analysis shows a considerable enrichment of motifs only consisting of A and $\mathrm{T}$ residues. Long stretches of these nucleotides upstream of the transcribed region are typical for Vaccinia virus and ASFV early promoters, as well as for ASFV late promoters $[18,20,30]$.

\section{WSSV}

The same enumeration method was used to analyze the upstream sequences of WSSV ORFs. The analysis of the 4and 5-mer motifs is shown in Table 1. Sequences of the consensus TATA box appear relatively frequently compared to their presence in the complete WSSV genome (Table 1). The enrichment of these TATA box sequences is similar to what is observed for AcMNPV and HHV1 (Table 1), indicating a functional role for the TATA box in WSSV transcription regulation. Besides the TATA box sequences, the sequence AACC has the highest enrichment in the 100 nt upstream sequences of WSSV ORFs, although not as pronounced as the occurrences of the AcMNPV TAAG motif (Table 1). Previous experiments showed that the TISs of the late WSSV envelope protein genes $v p 28$ and $v p 19$ start within this exact AACC sequence [31] indicating this could be a putative promoter element for late transcription. Furthermore, some motifs consisting of G and C residues, such as the 4-mers CCGG and CCCC and the 5mers CCGGG and CCCGG (Table 1), and G/C-rich sequences have a relatively high frequency in WSSV upstream regions. Compared to the $100 \mathrm{nt}$ upstream of the ORFs, the results for the analysis of $200 \mathrm{nt}$ are only slightly different and mostly less pronounced (Table 1 ). From the remaining analysis using 6,7 or 8 nt motifs in the 100 or $200 \mathrm{nt}$ upstream regions (data not shown), it is noteworthy that the enumeration method shows a relative enrichment of the 6-mer consensus TATA box sequence TATAAA of 4.7 times in the $100 \mathrm{nt}$ upstream of the ORFs.

Previously, we showed that the WSSV genes clustered in an early and a late class based on expression profile in shrimp tissue [16]. Further analysis within the $100 \mathrm{nt}$ upstream regions of either the WSSV early or late genes using the enumeration method showed that the sequence AACC has the highest relative enrichment of all possible 4-mer motifs for the late genes (2.4 times), while sequences of the TATA box were highly enriched in upstream regions of both gene classes (the sequence TATA showed a relative enrichment of 2.3 times in the $100 \mathrm{nt}$ 
Table I: Frequency of 4- or 5-nucleotide motifs in the 5' upstream regions of the ORFs as compared to the complete genome for the viruses AcMNPV, HHVI, Vaccinia virus, ASFV and WSSV. Only the 15 motifs with the highest relative enrichment are shown for each virus. For AcMNPV, HHVI and WSSV, sequences that are part of the consensus TATA box (TATA(a/t)A) are underlined, while for Vaccinia virus and ASFV sequences only consisting of $A$ and $T$ residues are italics. * Means $P \leq 0.05$

\begin{tabular}{|c|c|c|c|c|c|c|c|}
\hline $\begin{array}{l}\text { 4/5-mer } \\
\text { (motif) }\end{array}$ & $\begin{array}{l}\text { Occurrence in } \\
\text { genome } \\
\text { (\% of expected }^{\mathrm{a}} \\
\left.\text { occurrence }^{\mathrm{b}}\right)\end{array}$ & $\begin{array}{l}\text { Occurrence in } \\
\text { upstream regions (\% } \\
\text { of expected } \\
\text { occurrence }^{\text {b }} \text { ) }\end{array}$ & $\begin{array}{c}\text { Relative } \\
\text { enrichment } \\
\text { in upstream } \\
\text { regions }\end{array}$ & $\begin{array}{l}\text { 4/5-mer } \\
\text { (motif) }\end{array}$ & $\begin{array}{l}\text { Occurrence in } \\
\text { genome } \\
\left(^{\mathrm{a}} \text { of expected }\right. \\
\left.\text { occurrence }^{\mathrm{b}}\right)\end{array}$ & $\begin{array}{c}\text { Occurrence in } \\
\text { upstream regions (\% } \\
\text { of expected } \\
\left.\text { occurrence }^{\text {b }}\right)\end{array}$ & $\begin{array}{c}\text { Relative } \\
\text { enrichment } \\
\text { in upstream } \\
\text { regions }\end{array}$ \\
\hline
\end{tabular}

100 nt upstream

$200 \mathrm{nt}$ upstream

AcMNPV

\begin{tabular}{cccccccccccc}
\hline taagc & 393 & $(29)$ & 90 & $(114)$ & $4.0^{*}$ & taagc & 393 & $(29)$ & 137 & $(87)$ & $3.0^{*}$ \\
tata & 1314 & $(66)$ & 172 & $(149)$ & $2.3^{*}$ & tata & 1314 & $(66)$ & 255 & $(111)$ & $1.7^{*}$ \\
$\underline{\text { ataa }}$ & 1973 & $(101)$ & 222 & $(198)$ & $1.9^{*}$ & $\underline{\text { ataa }}$ & 1973 & $(101)$ & 363 & $(162)$ & $1.6^{*}$ \\
$\underline{\text { atat }}$ & 1616 & $(81)$ & 170 & $(147)$ & $1.8^{*}$ & $\underline{\text { atat }}$ & 1616 & $(81)$ & 268 & $(116)$ & $1.4^{*}$ \\
agta & 671 & $(49)$ & 70 & $(89)$ & $1.8^{*}$ & agta & 671 & $(49)$ & 109 & $(69)$ & $1.4^{*}$ \\
aagg & 473 & $(51)$ & 41 & $(76)$ & 1.5 & gata & 867 & $(63)$ & 137 & $(87)$ & 1.4 \\
gata $^{\text {d }}$ & 867 & $(63)$ & 74 & $(94)$ & 1.5 & aata & 2230 & $(115)$ & 346 & $(154)$ & 1.3 \\
cact $^{\text {eata }}$ & 612 & $(64)$ & 52 & $(95)$ & 1.5 & cagt & 698 & $(73)$ & 106 & $(96)$ & 1.3 \\
aata & 2230 & $(115)$ & 186 & $(166)$ & 1.4 & ctta & 393 & $(28)$ & 59 & $(37)$ & 1.3 \\
atta & 1957 & $(98)$ & 163 & $(141)$ & 1.4 & tcace & 669 & $(70)$ & 99 & $(90)$ & 1.3 \\
gtat & 949 & $(68)$ & 79 & $(98)$ & 1.4 & gcta & 541 & $(57)$ & 77 & $(70)$ & 1.2 \\
cagtf & 698 & $(73)$ & 58 & $(105)$ & 1.4 & cccc & 190 & $(42)$ & 27 & $(52)$ & 1.2 \\
taaa & 2716 & $(140)$ & 222 & $(198)$ & 1.4 & tacc & 444 & $(47)$ & 63 & $(57)$ & 1.2 \\
aggg & 233 & $(35)$ & 19 & $(50)$ & 1.4 & tagt & 737 & $(53)$ & 104 & $(64)$ & 1.2 \\
tagt & 737 & $(53)$ & 58 & $(72)$ & 1.4 & cacte & 612 & $(64)$ & 86 & $(78)$ & 1.2 \\
\end{tabular}

HHV I

\begin{tabular}{llllllllllll}
\hline ttag & 221 & $(53)$ & 17 & $(168)$ & $3.2^{*}$ & ataa & 372 & $(192)$ & 42 & $(445)$ & $2.3^{*}$ \\
ctag & 182 & $(20)$ & 13 & $(60)$ & $2.9^{*}$ & tata & 306 & $(159)$ & 32 & $(342)$ & $2.2^{*}$ \\
ctct & 658 & $(76)$ & 38 & $(180)$ & $2.4^{*}$ & ctag & 182 & $(20)$ & 19 & $(44)$ & $2.1^{*}$ \\
tagc & 365 & $(41)$ & 21 & $(97)$ & $2.4^{*}$ & taaa & 454 & $(234)$ & 47 & $(498)$ & $2.1^{*}$ \\
tcta & 199 & $(49)$ & 11 & $(111)$ & $2.3^{*}$ & cattg & 339 & $(83)$ & 35 & $(176)$ & $2.1^{*}$ \\
tttt & 807 & $(426)$ & 44 & $(955)$ & $2.2^{*}$ & taag & 254 & $(60)$ & 26 & $(127)$ & $2.1^{*}$ \\
tagg & 342 & $(38)$ & 17 & $(77)$ & $2.0^{*}$ & ttaa & 356 & $(185)$ & 35 & $(374)$ & $2.0^{*}$ \\
cata & 369 & $(90)$ & 18 & $(180)$ & $2.0^{*}$ & ctct & 658 & $(76)$ & 64 & $(152)$ & $2.0^{*}$ \\
ctta & 254 & $(62)$ & 12 & $(121)$ & $1.9^{*}$ & ttag & 221 & $(53)$ & 21 & $(104)$ & $2.0^{*}$ \\
ccta & 342 & $(39)$ & 16 & $(75)$ & 1.9 & cata & 369 & $(90)$ & 34 & $(170)$ & $1.9^{*}$ \\
tctc & 892 & $(103)$ & 41 & $(194)$ & 1.9 & ctta & 254 & $(62)$ & 23 & $(116)$ & $1.9^{*}$ \\
ctgt & 936 & $(106)$ & 40 & $(186)$ & 1.8 & tttt & 807 & $(426)$ & 72 & $(782)$ & $1.8^{*}$ \\
ctac & 492 & $(56)$ & 21 & $(99)$ & 1.8 & cctt & 795 & $(92)$ & 68 & $(161)$ & 1.8 \\
ttcc & 990 & $(114)$ & 42 & $(199)$ & 1.7 & aaat & 324 & $(167)$ & 27 & $(286)$ & 1.7 \\
cact & 433 & $(50)$ & 18 & $(85)$ & 1.7 & ctat & 242 & $(59)$ & 20 & $(101)$ & 1.7 \\
& & & & & & & & & & & \\
\hline
\end{tabular}

Vaccinia virus

\begin{tabular}{|c|c|c|c|c|c|c|c|c|c|c|c|}
\hline taaah & 4421 & (94) & 472 & $(140)$ & $1.5^{*}$ & gcac & 391 & $(66)$ & 77 & (9I) & $1.4^{*}$ \\
\hline aaaah & 5439 & (II5) & 564 & (167) & $1.5^{*}$ & ataa & 4528 & (96) & 822 & (I22) & $1.3^{*}$ \\
\hline ataa & 4528 & (96) & 446 & (133) & $1.4^{*}$ & $t a a a^{h}$ & 4421 & (94) & 796 & $(118)$ & $1.3 *$ \\
\hline aaath & 4454 & (94) & 432 & (I28) & $1.4^{*}$ & tact & 2010 & (85) & 353 & (105) & $1.2 *$ \\
\hline $\operatorname{cgcg}$ & 318 & (107) & 30 & (141) & $1.3 *$ & acta & 2179 & (92) & 373 & (III) & $1.2^{*}$ \\
\hline gggg & 171 & (57) & 16 & (75) & $1.3 *$ & aaath & 4454 & (94) & 755 & $(1 \mid 2)$ & 1.2 \\
\hline acac & 1112 & (94) & 103 & (122) & $1.3^{*}$ & aaaah & 5439 & $(115)$ & 911 & (135) & 1.2 \\
\hline aata & 5203 & $(110)$ & 479 & $(142)$ & $1.3^{*}$ & tgca & 832 & (70) & 138 & (82) & 1.2 \\
\hline ttaa & 3720 & (79) & 337 & $(100)$ & 1.3 & aata & 5203 & $(110)$ & 857 & (127) & 1.2 \\
\hline tact & 2010 & (85) & 179 & $(106)$ & 1.3 & ctac & 1264 & (107) & 208 & (123) & 1.2 \\
\hline acta & 2179 & (92) & 190 & $(1 \mid 3)$ & 1.2 & gccg & 384 & (129) & 63 & (148) & 1.2 \\
\hline tata & 4748 & (101) & 411 & (I22) & 1.2 & gcga & 500 & (84) & 82 & (97) & 1.2 \\
\hline tgaa & 1917 & (8I) & 165 & (98) & 1.2 & cacg & 586 & (98) & 96 & (II3) & 1.2 \\
\hline ctaa & 1830 & (77) & 157 & (93) & 1.2 & accc & 403 & (68) & 66 & (78) & 1.2 \\
\hline gtaa & 1921 & $(81)$ & 164 & (97) & 1.2 & cata & 2186 & (92) & 358 & (106) & 1.2 \\
\hline
\end{tabular}


Table I: Frequency of 4- or 5-nucleotide motifs in the 5' upstream regions of the ORFs as compared to the complete genome for the viruses AcMNPV, HHVI, Vaccinia virus, ASFV and WSSV. Only the 15 motifs with the highest relative enrichment are shown for each virus. For AcMNPV, HHVI and WSSV, sequences that are part of the consensus TATA box (TATA(a/t)A) are underlined, while for Vaccinia virus and ASFV sequences only consisting of $A$ and $T$ residues are italics. * Means $\mathbf{P} \leq 0.05$ (Continued)

\begin{tabular}{|c|c|c|c|c|c|c|c|c|c|c|c|}
\hline tata & 2686 & (91) & 261 & (199) & $2.2^{*}$ & tata ${ }^{\mathrm{i}}$ & 2686 & (91) & 405 & (154) & $1.7^{*}$ \\
\hline ataa & 3146 & (107) & 278 & $(2 \mid 4)$ & $2.0^{*}$ & ataa & 3146 & $(107)$ & 432 & $(166)$ & $1.5^{*}$ \\
\hline aatt & 2634 & (89) & 231 & $(176)$ & $2.0^{*}$ & aatt & 2634 & (89) & 357 & (136) & $1.5^{*}$ \\
\hline taat & 2697 & (91) & 227 & $(173)$ & $1.9 *$ & taaa & 3895 & (133) & 516 & (198) & $1.5^{*}$ \\
\hline taaa & 3895 & (133) & 325 & $(250)$ & $1.9 *$ & ttaa & 3376 & $(1 \mid 4)$ & 447 & $(170)$ & $1.5^{*}$ \\
\hline aata & 3419 & $(117)$ & 278 & $(2 \mid 4)$ & $1.8^{*}$ & aata & 3419 & $(117)$ & 445 & (I7I) & $1.5^{*}$ \\
\hline ttaa & 3376 & $(114)$ & 274 & (209) & $1.8^{*}$ & atat & 3022 & $(102)$ & 392 & (149) & $1.5^{*}$ \\
\hline atat & 3022 & $(102)$ & 238 & (182) & $1.8^{*}$ & taat & 2697 & $(91)$ & 349 & (133) & $1.5^{*}$ \\
\hline$a t t t$ & 3890 & $(|3|)$ & 306 & $(231)$ & $1.8^{*}$ & ttat & 3146 & $(106)$ & 406 & (154) & $1.5^{*}$ \\
\hline ttat & 3146 & $(106)$ & 247 & (187) & $1.8^{*}$ & attt & 3890 & $(131)$ & 495 & (187) & $1.4^{*}$ \\
\hline$t t t a$ & 3895 & $(131)$ & 296 & $(224)$ & $1.7^{*}$ & ctaa & 1172 & (63) & 147 & (88) & $1.4^{*}$ \\
\hline atta & 2697 & (91) & 203 & (I55) & $1.7^{*}$ & atta & 2697 & (91) & 337 & (I29) & $1.4^{*}$ \\
\hline tatt & 3419 & $(115)$ & 249 & (188) & $1.6 *$ & tatt & 3419 & $(115)$ & 426 & $(161)$ & $1.4^{*}$ \\
\hline aaaa & 6731 & $(232)$ & 480 & (372) & $1.6^{*}$ & $t t t a$ & 3895 & $(131)$ & 482 & $(182)$ & $1.4^{*}$ \\
\hline aaat & 3890 & (133) & 272 & (209) & $1.6 *$ & aaaa & 6731 & $(232)$ & 828 & $(321)$ & $1.4^{*}$ \\
\hline
\end{tabular}

WSSV (4-mer motif)

\begin{tabular}{|c|c|c|c|c|c|c|c|c|c|c|c|}
\hline tata & 2630 & $(60)$ & 164 & $(128)$ & $2.2^{*}$ & tata & 2630 & $(60)$ & 290 & $(1 \mid 7)$ & $2.0 *$ \\
\hline$\overline{\text { ataaj }}$ & 3431 & (74) & 201 & $(150)$ & $2.0 *$ & $\overline{\text { ataaj }}$ & 3431 & (74) & 327 & $(126)$ & $1.7^{*}$ \\
\hline taaa & 3538 & (77) & 195 & (146) & $1.9 *$ & $\overline{\mathrm{accc}}$ & 1333 & (88) & 127 & (148) & $1.7^{*}$ \\
\hline$\overline{\text { aacc }}$ & 1774 & (79) & 92 & (142) & $1.8 *$ & taaa & 3538 & (77) & 333 & (128) & $1.7^{*}$ \\
\hline aaaa & 6450 & (134) & 330 & (236) & $1.8^{*}$ & $\overline{\text { aaaa }}$ & 6450 & (I34) & 570 & $(210)$ & $1.6 *$ \\
\hline accc & 1333 & (88) & 68 & (I54) & $1.8^{*}$ & ccgg & 374 & (36) & 33 & $(56)$ & $1.6 *$ \\
\hline accg & 699 & (46) & 33 & $(75)$ & $1.6 *$ & $\operatorname{cccc}$ & 1348 & $(130)$ & 118 & (202) & $1.6 *$ \\
\hline tacc & 1424 & (67) & 64 & $(103)$ & 1.5 & cacg & 995 & $(65)$ & 86 & $(100)$ & $1.5^{*}$ \\
\hline caac & 2792 & (125) & 123 & $(190)$ & 1.5 & aacc & 1774 & (79) & 150 & $(119)$ & $1.5^{*}$ \\
\hline aata & 4104 & (89) & 179 & (I34) & 1.5 & accg & 699 & $(46)$ & 56 & $(65)$ & 1.4 \\
\hline $\mathrm{tttt}$ & 6450 & $(160)$ & 281 & $(240)$ & 1.5 & taac ${ }^{\mathrm{j}}$ & 1888 & $(60)$ & $15 \mid$ & (85) & 1.4 \\
\hline taaci & 1888 & $(60)$ & 82 & $(90)$ & 1.5 & gtaa & 1810 & (58) & 144 & $(81)$ & 1.4 \\
\hline cccg & 583 & (56) & 25 & (83) & 1.5 & taag & 1402 & $(45)$ & 109 & $(6 I)$ & 1.4 \\
\hline ccgg & 374 & (36) & 16 & (53) & 1.5 & gggt & 1333 & (91) & 103 & (I24) & 1.4 \\
\hline $\operatorname{ccg} t$ & 940 & (64) & 40 & (94) & 1.5 & $\mathrm{tttt}$ & 6450 & $(160)$ & 491 & $(216)$ & 1.3 \\
\hline
\end{tabular}

WSSV (5-mer motif)

\begin{tabular}{|c|c|c|c|c|c|c|c|c|c|c|c|}
\hline ccggg & 66 & (3I) & 7 & $(1 \mid 6)$ & $3.8^{*}$ & tataa & 760 & (57) & 113 & $(151)$ & $2.6^{*}$ \\
\hline tataa & 760 & (57) & 73 & (195) & $3.4^{*}$ & $\overline{\mathrm{cccccc}}$ & 292 & (137) & 41 & (342) & $2.5^{*}$ \\
\hline cccgg & 66 & (3I) & 6 & (99) & $3.2^{*}$ & atata & 716 & $(54)$ & 95 & $(127)$ & $2.4^{*}$ \\
\hline ataaa & 1202 & (87) & 103 & $(263)$ & $3.0^{*}$ & ataaa & 1202 & (87) & 147 & (188) & $2.2^{*}$ \\
\hline taaaa & 1378 & (99) & 102 & $(261)$ & $2.6^{*}$ & $\overline{\operatorname{ccggg}}$ & 66 & $(31)$ & 8 & $(66)$ & $2.1^{*}$ \\
\hline aaccg & 203 & (44) & 15 & $(116)$ & $2.6^{*}$ & taaaa & 1378 & (99) & 167 & $(2 \mid 3)$ & $2 . I^{*}$ \\
\hline gtata & 609 & (67) & 45 & $(176)$ & $2.6^{*}$ & gtata & 609 & (67) & 73 & (I43) & $2.1^{*}$ \\
\hline atata & 716 & (54) & 51 & (I36) & $2.5^{*}$ & aaccg & 203 & (44) & 23 & (89) & $2.0 *$ \\
\hline taccc & 331 & (75) & 22 & $(178)$ & $2.4^{*}$ & aaaaa & 2054 & $(142)$ & 231 & $(283)$ & $2.0^{*}$ \\
\hline acccg & 138 & (44) & 9 & $(102)$ & $2.3^{*}$ & tatat & 716 & (56) & 79 & $(110)$ & $2.0^{*}$ \\
\hline aaaaa & 2054 & (I42) & 133 & (325) & $2.3^{*}$ & $\operatorname{acccc}$ & 320 & $(103)$ & 35 & (199) & $1.9 *$ \\
\hline aacca & 644 & $(96)$ & 41 & $(216)$ & $2.3^{*}$ & accgg & 120 & $(38)$ & 13 & (73) & $1.9 *$ \\
\hline ccgta & 208.0 & (47) & 13 & (105) & $2.2^{*}$ & cccgg & 66 & (3I) & 7 & (58) & $1.9 *$ \\
\hline gacct & 257 & (58) & 16 & (129) & $2.2^{*}$ & $\operatorname{ctcac}^{\mathrm{k}}$ & 284 & $(65)$ & 30 & $(121)$ & $1.9 *$ \\
\hline cgtcg & 178 & (59) & 11 & $(130)$ & $2.2^{*}$ & taccc & 331 & (75) & 34 & (137) & I.8* \\
\hline
\end{tabular}

aboth strands, excluding hrs (present for AcMNPV and WSSV)

bexpected occurrence is the occurrence of a 4-mer or 5-mer based on random distribution of nucleotides in the complete genome cpart of the AcMNPV late initiator sequence $(\mathrm{a} / \mathrm{g} / \mathrm{t}) \mathrm{TAAG}$

dpart of the ACMNPV upstream activating element with sequence $(a / t) G A T A(a / t)$

epart of the AcMNPV downstream activating element with sequence $(a / t) C A C N G$

fsequence of the AcMNPV early initiator CAGT

gpart of the CCATT box

hpart of the Vaccinia virus late initiator sequence TAAAT and/or the intermediate initiator TAAA(a/t)

isequence of the ASFV late initiator TATA

ipart of the WSSV putative late TIS motif ATNAC

kpart of the WSSV putative early initiator $(\mathrm{a} / \mathrm{c})$ TCANT 
Table 2: Consensus sequences (4-8 nt) in upstream regions of WSSV genes identified with MEME. Only the best 3 hits of MEME are shown. In case of all WSSV genes, the number of sequences in which the consensus sequence occurred is indicated.

\begin{tabular}{|c|c|c|c|}
\hline & $\begin{array}{c}\text { All WSSV genes ( } 0 \text { or I occurrence } \\
\text { per individual sequence) }\end{array}$ & $\begin{array}{l}\text { Early WSSV genes (I occurrence } \\
\text { per individual sequence) }\end{array}$ & $\begin{array}{l}\text { Late WSSV genes (I occurrence } \\
\text { per individual sequence) }\end{array}$ \\
\hline I 00 nt upstream & $\begin{array}{c}\text { gtataaaa (TATA box) (6I seqs) } \\
\text { tgtttttt (T-rich) (65 seqs) } \\
\text { gaggaaga (6I seqs) }\end{array}$ & $\begin{array}{c}\text { gtataaaa (TATA box) } \\
\text { ttttttca (T-rich) } \\
\text { caacatca }\end{array}$ & $\begin{array}{c}\text { gtataaaa (TATA box) } \\
\text { tttgtgta } \\
\text { aacc }\end{array}$ \\
\hline 200 nt upstream & $\begin{array}{c}\text { gtataaaa (TATA box) (I I } 2 \text { seqs) } \\
\text { ttgttttt (T-rich) (65 seqs) } \\
\text { tcctcctc }(6 \mathrm{I} \text { seqs) }\end{array}$ & $\begin{array}{c}\text { agaagagg } \\
\text { tatttttt (T-rich) } \\
\text { agaaat }\end{array}$ & $\begin{array}{c}\text { gaggaaga } \\
\text { tcttttat (T-rich) } \\
\text { aaaaatat (A-rich) }\end{array}$ \\
\hline
\end{tabular}

upstream regions of both gene classes; other data not shown).

\section{MEME}

The 100 or $200 \mathrm{nt}$ sequences upstream of all WSSV genes were also studied by MEME (Table 2). As multiple classes of coregulated viral genes will be present within these sequences, the MEME settings for this analysis were to identify conserved motifs regardless whether it occurred in the upstream regions of all genes. MEME identified the TATA box as consensus nucleotide motif in these WSSV upstream sequences (Table 2). Furthermore this analysis showed that multiple upstream sequences contain stretches of $\mathrm{T}$ residues (Table 2). Analysis on the location and composition of these sequences revealed that these are mostly part of the polyadenylation signals [32] of the upstream ORFs, and therefore probably not functional as promoter element of WSSV. The outcome of the 100 and $200 \mathrm{nt}$ upstream sequences are very similar, in line with the results of the enumeration method.

For individual analysis of the WSSV early or late kinetic cluster [16] the frequency of a specific motif per individual sequence was set at one, as most WSSV genes belonging to one cluster were considered to be coregulated. Analysis of the 100 and $200 \mathrm{nt}$ upstream regions of either the early or the late class genes identified the consensus TATA box as putative promoter element (Table 2). Previously, we already showed that 37 of the 64 early genes (58\%) and 28 of the 58 genes that clustered late (48\%) contain a consensus TATA box [16]. Specific for the early class, MEME identified the consensus sequences CAACATCA and AGAAT, while for the late class it identified the consensus sequence AACC as well as an A-rich region (Table 2). On the other hand, as the early or late kinetic cluster [16] could also consist of subsets of coregulated WSSV genes, an additional MEME analysis was performed in which a motif only had to occur in at least half of the upstream sequences of either the early or the late genes. The outcome was very similar to the results presented in Table 2. Interestingly, the TATA box and the AACC motif were identified by the enumeration method as being highly enriched in upstream regions of WSSV ORFs.

\section{Alignments TISs of WSSV genes}

To validate both in silico methods described above, we compared the outcome with alignments of all known $5^{\prime}$ ends of the WSSV early and late class genes. To facilitate comparisons with other viruses, in these alignments the function of the protein encoded by the gene is used to determine its class, either early or late. Early genes often encode enzymes which have functions involved in processes such as nucleotide metabolism, DNA replication, protein modification, viral transcription initiation and host response modulation. Structural virion protein genes often comprise a large part of viral late genes. For nearly all WSSV genes analyzed, this classification matched the results obtained by the microarray study [16].

\section{Early genes}

The WSSV genome encodes around 10 genes which, based on their (putative) function, are considered to be early [10]. For several of these genes the 5' end of their transcripts has been mapped. RT-PCRs and/or Northern Blots of viral time courses confirmed that these genes were expressed in an early stage during infection (for references see Fig. 1). Furthermore ORF89, which is thought to be involved in latency, was empirically shown to be (immediate) early [33,34]. Fig. 1 shows an alignment of the experimentally determined transcription initiation sites (TISs) of WSSV early genes. The genes typically contain a consensus TATA box (sequence: TATA(a/t)A) [35]. The TIS is located 20 to 30 nucleotides downstream of the consensus TATA box, which is considered to be a functional distance [35-37]. This is between 20 to 85 nucleotides upstream of the translational start codon of the early gene products (Fig. 1). When the sequences are aligned by maximizing the identities around the transcriptional start site (Fig. 1), a clear consensus transcription initiation motif $((\mathrm{a} / \mathrm{c})$ TCANT) overlapped with the transcriptional start sites. This resembles the RNA polymerase II core promoter motif identified in Drosophila, which often consists of a consensus TATA box and/or an initiator with the sequence (A)TCA $(+1)(\mathrm{g} / \mathrm{t}) \mathrm{T}(\mathrm{t} / \mathrm{c})$ [35-38]. Similar to WSSV, the initiator of Drosophila is typically located 25-30 nt downstream of a TATA box [35-37]. Interestingly, the motif CTCAC, which is part of the identified WSSV consensus 


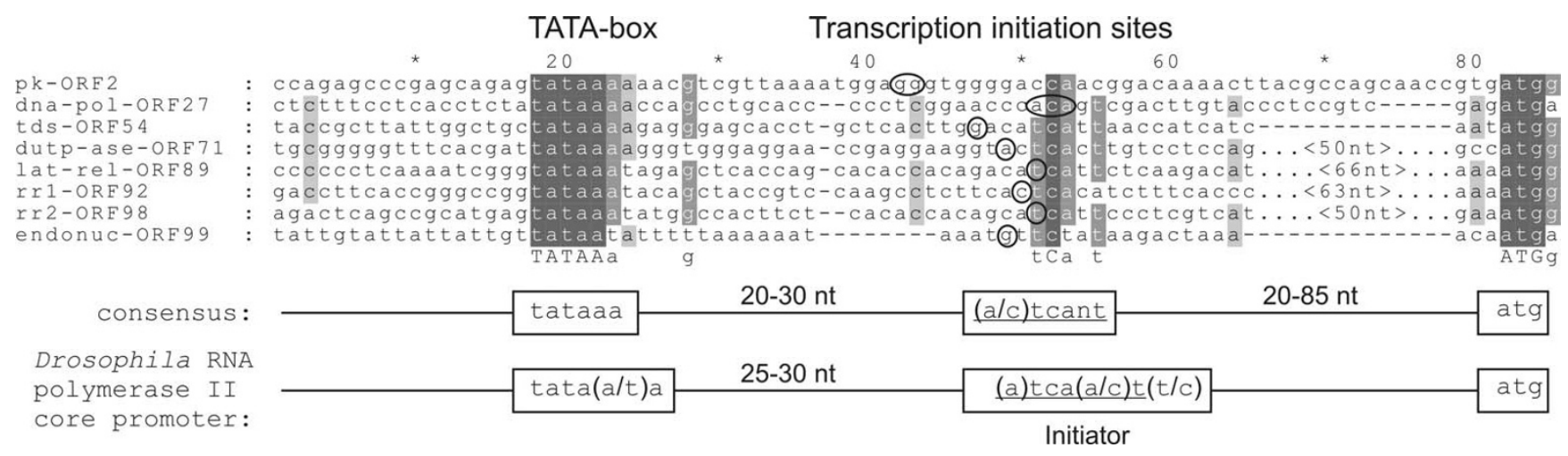

Figure I

Alignment of 5' flanking sequences of WSSV early genes. The genes are named after WSSV-TH ORF numbers and the function of their protein product. The transcription initiation site of each gene is encircled. Sequences are aligned by their consensus TATA box, as well as by maximizing the identities around the transcriptional start site. Below, the consensus sequence of the alignment and the Drosophila RNA polymerase II core promoter are shown. Similar sequences of the consensus TIS motif and the initiator of the Drosophila RNA pol II core promoter are underlined. Abbreviations used and references: pk: protein kinase [52]; DNA-pol: DNA polymerase [47]; $t d s$ : Thymidylate Synthase [48]; dutp-ase: dUTPase [42]; lat-rel: latency related gene [33]; $r r l$ and $r r 2$ : the large and small subunit of ribonucleotide reductase, respectively [53]; endonuc: endonuclease [54].

sequence $(\mathrm{a} / \mathrm{c}) \mathrm{TCANT}$ and which is the exact sequence of the TISs of the dutpase and $r r 1$ (Fig. 1), was also shown to be enriched in upstream regions of WSSV ORFs (Table 1).

\section{Late genes}

The protein pattern of WSSV particles on an SDS-PAGE gel shows around 8 major WSSV structural virion proteins [12-15]. For 6 of these proteins (VP664, VP28, VP26, VP24, VP19 and VP15) the 5' end of the corresponding mRNA has been mapped [31,39]. RT-PCRs and/or Northern Blots of viral time courses confirmed that these genes were expressed in a late stage during infection [31,39]. We completed this analysis by mapping the TISs of the two other major structural protein genes, vp75 (ORF160) and $v p 73$ (ORF112). Both $v p 75$ and $v p 73$ lack a consensus TATA box (Fig. 2a). Using 5'RACE, the TIS of $v p 75$ was identified within the nucleotide sequence TG, $72 \mathrm{nt}$ upstream of the translational start codon. For $v p 73$, the TIS was located at nucleotide residues TC, 220 upstream of the translational start codon (Fig. 2a).

When the upstream sequences of all major structural protein genes are aligned by maximizing the identities around the transcriptional start sites (Fig. 3), the TISs are present within or very near the nucleotide sequence ATNAC. The transcripts start 20-25 nucleotides downstream of an $\mathrm{A} / \mathrm{T}$ rich region, which has an average $\mathrm{A} / \mathrm{T}$ content of $79 \%$ compared to $61 \%$ of the $200 \mathrm{nt}$ upstream regions of the 8 genes. $V p 15$ and $v p 19$ contain a consensus TATA box, of which only the TATA box of $v p 15$ is at a functional distance of the TIS (Fig. 3) [31]. The length of the TIS to the translational start codon is different for the var- ious genes, ranging from 30 to $220 \mathrm{nt}$ (Fig. 3). Interestingly, most of these features were predicted by our in silico analysis. The first three nucleotides of the AACC motif identified in the in silico analysis (Tables 1 and 2) are part of the consensus sequence ATNAC, and both contain the $\mathrm{AC}$ dinucleotide which is present for almost all genes in Fig. 3. Also the sequences ATAA and TAAC, parts of the ATNAC sequence, were identified as putative promoter elements (Table 1). Of all WSSV late genes, as assigned by microarray analysis [16], 40\% (23 of the 58, both structural and non-structural protein genes) contains the sequence ATNAC in their $100 \mathrm{nt}$ upstream region. The Arich (and T-rich) sequences identified by MEME are in line with the observation that late genes often contain long stretches of A/T residues upstream of their TIS (Fig. 3).

In addition to the 8 major structural proteins, the protein profile of WSSV particles shows a range of about 40 minor virion proteins $[12,13]$. Most of these have not been studied in detail. However, the corresponding messengers are supposed to be late, although 13 of them clustered in the early class during microarray analysis [16]. Remarkably, $45 \%$ of the minor virion protein genes ( 18 of the 40 ) contain a consensus TATA box within $300 \mathrm{nt}$ of the translational start codon. This is in line with the MEME analysis, which also suggested that the TATA box might be involved in late transcription.

\section{Polyadenylation}

For various WSSV genes, the site of polyadenylation has been mapped using 3'RACE. We extended this analysis by mapping the polyadenylation site of ORF30, the collagen- 
(a)
VP75: gtcatgatttttgtggtgctggtaaagtagtttttgtacacgctgcaatatcttcgaccttaaatgtcttcggt taaagggatatttatttgttggtactgttttcgtcaaggctgaaaaataatttcaaatatacalatg
VP73: tttttctatttcgcaggttttcttatgtgtatcacaccagatctttcatcgggcgtaaaattgttctggacaa ttttcataccaatataggaaataatagaaataaacacaacgagaagcgtgaattcaaaggcaccccaccacgag ccaaaatacccgtgactgctgtttctccaaacattgttattgctgttcttaacggcagggttggttgttcggc aaatcaaggaaacaaaaagttacccgggcatg

(b)

\section{Downstream sequence, showing 3' RACE result}

ORF30: taalaattggttaataaataaaggtatatttttaaaaaatgtgtttatttttccccaaccttaaacagatc $5 * \underset{\longrightarrow}{\longrightarrow}$

Figure 2

Sequences upstream of two major structural protein genes vp75(ORF I 60) en vp73 (ORF I I 2) of WSSV showing the transcription initiation sites of both genes. The TISs are indicated by arrows above the sequences. The 5 ' termini of the different clones sequenced for each gene are underlined. The number beneath the underlining shows the number of similar clones. The start codons of both genes are shaded black (A). Sequence downstream of ORF30 showing the polyadenylation site, indicated by an arrow below the sequence. The $3^{\prime}$ terminus of the different clones sequenced is underlined. The number before the arrow represents the number of similar clones sequenced. The stop codon is shaded dark grey and two overlapping poly $(\mathrm{A})$ signals (AATAAA) light grey $(\mathbf{B})$.

like ORF of WSSV [40]. Polyadenylation of ORF30 starts $32 \mathrm{nt}$ after the translational stop codon, $16 \mathrm{nt}$ after the first poly(A)-signal (sequence AATAAA; Fig. 2b) [41].

Fig. 4 shows an alignment of all known polyadenylation sites of WSSV. Polyadenylation typically starts within $11-$ $19 \mathrm{nt}$ after a consensus polyadenylation site. Typically, a T rich region (stretch of about twelve $T$ residues) was identified $8 \mathrm{nt}$ downstream of the poly(A)-site (Fig. 4). There seems to be no difference between the polyadenylation sites of early and late genes (Fig. 4). A total of 9 WSSV genes were found to be non-polyadenylated $[13,42]$. Except for $v p 12 a$ (WSSV-TH ORF34), all these genes lack a consensus poly(A)-signal within -50 to $300 \mathrm{nt}$ of their translational stop codon. Two $(v p 31$ and $v p 13 b$ encoded by WSSV-TH ORF163 and ORF155, respectively) do however contain the sequence ATTAAA within this region, which in vertebrates is often sufficient for polyadenylation [43], but apparently not in invertebrates or arthropods.

\section{Discussion}

In this paper, we used a new enumeration strategy based on a model proposed by Brazma et al. [44] to identify putative WSSV promoter elements. A set of computer scripts was designed, which calculated the difference in nucleotide motif frequencies in the upstream sequences of all genes compared to the complete WSSV genomic sequence. The rationale behind this analysis is that promoter motifs are often thought to be transcription factor binding sites, which are functional upstream of genes. The results obtained with the well studied large ds DNA viruses AcMNPV, HHV1, Vaccinia virus and ASFV (Table 1 ) show that our method is robust in identifying important promoter elements of completely sequenced viral genomes without a priori knowledge, as these are often enriched in upstream sequences of viral ORFs. Therefore, this new enumeration method can be useful in the analysis of newly sequenced genomes of large ds DNA viruses. For further analysis of the upstream regions of WSSV genes of the early and late cluster, as assigned by microarray analysis [16], MEME was used. Genes of either cluster might be coregulated by similar mechanisms, utilizing conserved nucleotide motifs. As MEME can identify motifs which have to occur in each individual sequence of a set of submitted sequences, or in a selected number of submitted sequences, it is highly complementary to the enumeration method. Another advantage of MEME is that it can identify degenerate motifs.

The enumeration method identified various nucleotide motifs (Table 1) that were also identified by MEME (Table 


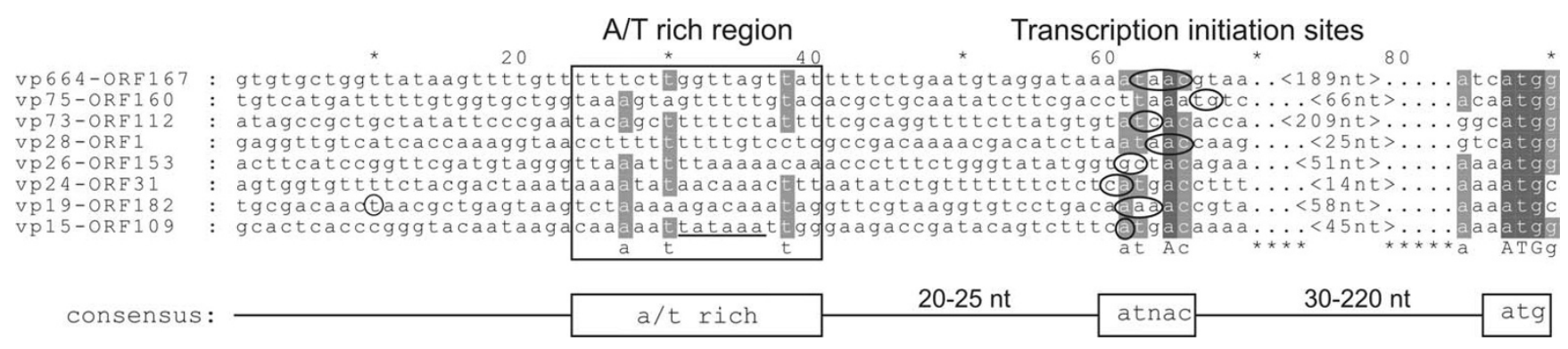

\section{Figure 3}

Alignment of 5' flanking sequences of WSSV late genes. Name of structural protein genes as well as WSSV-TH ORF numbers are indicated. The transcription initiation site of each gene is encircled. For $v p / 9$ a minor transcription initiation site is also encircled. The TATA box for $v p / 5$ is underlined. The A/T rich region is boxed. Sequences are aligned by maximizing the identities around the transcriptional start site. References: vp28, vp26, vp24, vp/9 and vp/5 [31]; vp664 [39]; vp75 and vp73 (this study).

2) and by the alignments of experimentally determined 5' ends of WSSV mRNAs (Figs. 1 and 3). These include the consensus TATA box, as well as the nucleotide motif AACC. However, also other nucleotide motifs that were not validated with the other methods, e.g. some motifs rich in C or G residues, were (highly) enriched in WSSV upstream regions and might be involved in WSSV transcription. In accordance with the alignments shown in Figs. 1 and 3, where most putative promoter elements are located within $100 \mathrm{nt}$ upstream of the ORFs, the nucleotide motifs identified with the enumeration method are most pronounced in the $100 \mathrm{nt}$ upstream of the ORFs (Table 1) compared to $200 \mathrm{nt}$. This suggests that, similar to AcMNPV, most WSSV promoter elements are located within 100 nt upstream of the translational start codons, which is a reflection of the tight package of genes along the WSSV genome. It would be of interest to test the functionality of the sequences $(\mathrm{a} / \mathrm{c}) \mathrm{TCANT}$ and ATNAC, which were identified as the consensus TISs of the WSSV early and late class genes, respectively (Fig. 3) and other identified motifs (Table 1) in a reporter gene (e.g. luciferase) assay. For testing late promoters in this setup, a co-infection with WSSV should be considered to supply additional viral transcription factors required for late gene expression. In the absence of a suitable WSSV cell system, these reporter gene assays have been performed in the artificial Sf9 insect cell line $[17,33,45]$ with all its limitations to the interpretation of the results. However, with the recent developments concerning differentiation and growth of crayfish hematopoietic stem cells in vitro [46], these experiments might be performed in crayfish cell cultures providing a more convenient and homologous system.

The identification of (putative) promoter elements provides further insight in the transcription mechanisms used by WSSV. The presence of a consensus TATA box for most early genes as well as a conserved transcription initiation motif similar to the Drosophila initiator suggest that WSSV uses the host RNA polymerase II transcription machinery for generating early transcripts, as also proposed by Chen et al. [47] and Liu et al. [42]. Previous analysis of WSSV late genes could not reveal any readily apparent dominant nucleotide element used for WSSV late gene expression [31]. Using the newly available microarray clustering [16], we could now show that around half of the WSSV putative late genes contain a consensus TATA box. This suggests that WSSV might exploit the cellular RNA polymerase II system not only for early but also for (part of) its late mRNA synthesis, similar to some other ds DNA viruses like herpesviruses [22]. Only one of the 8 major structural virion protein genes, which are expressed in the late phase of viral infection and most likely are co-regulated to secure correct assembly of the virion, contains a consensus TATA box. Alignment of the 5' ends of the 8 major structural protein genes identified a novel consensus transcription initiation site, ATNAC, downstream of an A/T rich region. The in silico analysis further supports the observation that both components might be late promoter elements. This suggests a second pathway for WSSV late gene expression, similar to the late gene expression strategy identified for baculoviruses $[23,24]$. However, different from baculoviruses, viral genes required for this pathway, such as a RNA polymerase or late transcription factors, have not been identified on the WSSV genome $[10,11]$. These genes could however be too much diverged from known homologues to be found based on amino acid homology.

The alignments of the 3 ' ends of WSSV mRNAs suggest that there is no difference in polyadenylation between early and late mRNAs. The WSSV polyadenylation characteristics of both classes resemble regular polyadenylation in eukaryotic mRNAs, which is typically located 10 to 25 nt downstream of the sequence AATAAA [41,43]. Also oligo- $T$ stretches are often present about $30 \mathrm{nt}$ downstream of the poly(A)-signal of eukaryotic genes [32]. 


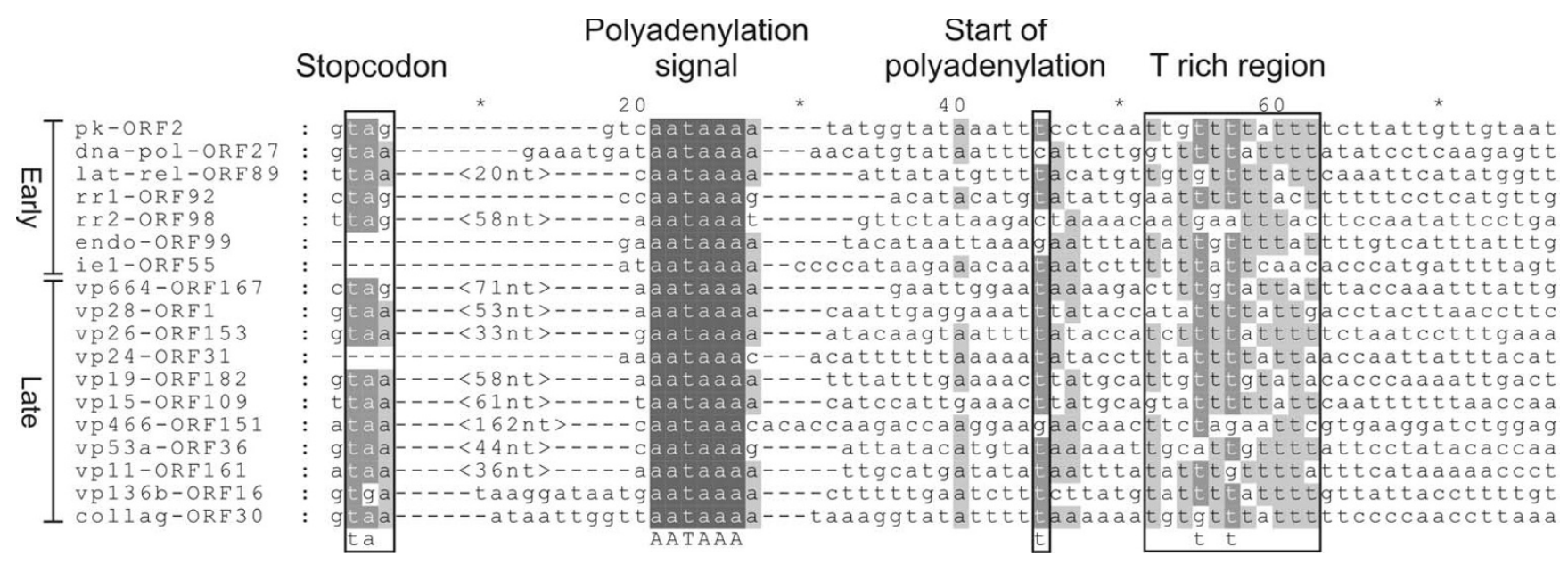

Figure 4

Alignment of 3' flanking sequences of WSSV genes. The stop codon, polyadenlylation signal, start of polyadenylation and the $T$ rich region are indicated. Sequences are aligned by stop codon and by polyadenylation signal. Abbreviations used and references: ie I: immediate-early I [I7]; vp466 [I2]; vp53a, vp II, vp/36b [I3]; collag: collagen-like ORF (this study). For abbreviations and references of other genes see Figs. I \& 3.

These data indicate that WSSV uses the regular cellular enzymes for polyadenylation of mRNAs. However, other undefined signal pathways of polyadenylation might also be used, as two WSSV genes (dUTPase and TdS) were found to be polyadenylated without a poly(A)-signal present $[42,48]$.

\section{Conclusion}

Using a combined approach of in silico analysis and experimentally determined data on WSSV transcriptomics, further support was found for the presence of different coregulated classes of WSSV genes. Comparisons with other large ds DNA viruses provided insight in the transcription mechanism of these classes and putative promoter motifs involved. In order to determine the functionality of these motifs empirically cell culture systems for shrimp will have to be further developed.

\section{Methods \\ Virus infection}

The virus isolate used in this study, known as WSSV-TH (acc.no. AF369029), originates from infected Penaeus monodon shrimp obtained in Thailand in 1996 and was treated as described before [15]. Crayfish Orconectes limosus was injected intramuscularly with purified WSSV using a 26-gauge needle to initiate infection. Three days post infection (d.p.i.), the crayfish were frozen in liquid nitrogen and stored at $-80^{\circ} \mathrm{C}$ until further use.

\section{5 ' and 3' Rapid Amplification of cDNA ends (5'/3' RACE)} Both 5' and 3' RACE were carried out using a commercial 5'/3' RACE kit (Roche) following the manufacturer's instructions. Total RNA was isolated from the frozen gill tissue of three infected crayfish O. limosus (harvested 3 d.p.i.) as described before [31]. In case of the 3' RACE of ORF30, first strand cDNA was synthesized using the oligo(dT) anchor primer. The resulting cDNA was amplified using one specific forward primer (ORF30-RACE-F1: CAGACCCGATTACAGTAGCAG; WSSV-TH location: 48983-49003) and the anchor primer. For the 5' RACE of ORF112 and ORF160, the RACE-R1 primers mentioned below were used for synthesis of the cDNA. This cDNA was purified using the High Pure PCR Product Purification Kit (Roche) and a homopolymeric 3' d(A)-tail was added to the cDNA in a mixture with a total volume of 20 $\mu \mathrm{l}$, using terminal transferase and dATPs included in the kit. This mixture $(5 \mu \mathrm{l})$ was used in a PCR, performed with an oligo(dT) anchor primer and a nested RACE-R2 primer (see below). The final products of the 5' and 3' RACE were cloned into the pGEM-T easy vector (Promega) and sequenced. For each 5' and 3' RACE at least 3 clones were sequenced. Primers used for 5' RACE: ORF112-RACE-R1: CGCATATTGTTGTTTGTCGTAG (WSSV-TH location 168230-168209); ORF112-RACE-R2: GACGCGTATCTCAAGTATTCC (WSSV-TH location 168184-168164); ORF160-RACE-R1: CTTGTTGGATTCGGAGCAGTG (WSSV-TH location 240137-240117); ORF160-RACE-R2: GACGGATAATATGGGTGACAAG (WSSV-TH location 240111-240090).

\section{DNA sequencing and computer analysis}

Plasmid clones carrying RACE products were sequenced at the company BaseClear (the Netherlands), using universal M13 forward and reverse primers. Sequence data were 
analyzed using the software package DNASTAR4.2. All sequences data were edited and aligned in GeneDoc, version 2.6.000 [49].

\section{Promoter analysis using the enumeration method}

A set of computer scripts, made in the computer programming language Perl (see [50] for more information), was designed to analyze all 4, 5, 6, 7 or 8 nucleotide motif frequencies in the 100 and 200 nt upstream sequences of (putative) ORFs to compare these with a complete viral genome. In case of WSSV, the genome of WSSV-TH as annotated by van Hulten et al. [10] was used for the analysis. For WSSV and Autographa californica Multinucleopolyhedrovirus (AcMNPV), the genes and upstream regions of genes that are partly or completely located in the homologous regions ( $h r s$, genomic regions consisting of large tandem repeats; for WSSV this concerns 24 genes, for AcMNPV 3 genes) and the hrs itself were excluded from the analysis to avoid the possibility of finding false motifs due to the high homology of the $h r$ sequences. As nucleotide motifs with a regulatory function are expected to be present in multiple upstream regions, only motifs that were present in upstream sequences of at least 5 ORFs were analyzed after running the scripts. Scripts were used for the following procedures: (1) extraction of the upstream region before the selected ORFs, both on the + and - strand; (2) calculation of the X-mer nucleotide motif frequencies in the upstream regions; (3) calculation of the $\mathrm{X}$-mer nucleotide motif occurrences in both strands of the viral genome (without $h r s$ ); (4) calculation of the relative ratio of the same X-mers between the upstream regions and the viral genome; (5) ranking of the relative ratios for each X-mer from high to low; (6) exclusion of motifs present in less than 5 upstream regions. Accession numbers of genomes analyzed were AcMNPV [Genbank:

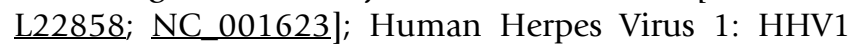
[Genbank: X14112; NC 001806]; Vaccinia virus [Genbank: M35027]; African Swine Fever Virus: ASFV [Genbank: U18466; NC 001659]]) and WSSV [Genbank: AF369029]. Statistical analysis was performed by assuming a normal distribution of the enrichment of the nucleotide motifs for each of the viruses analyzed. $\mathrm{P} \leq 0.05$ in case the enrichment of a certain motif exceeds two times the standard deviation from the average enrichment.

\section{MEME}

The computer program Motif Elucidation using Maximum Expectation maximization (MEME; available at [51]) was used to search for specific sequence motifs in 100 or $200 \mathrm{nt}$ of the WSSV noncoding sequences upstream of the translational initiation codon. MEME analysis was performed using the sequence of WSSV-TH annotated by van Hulten et al. [10]. A search was performed for the 3 best motifs with a length of 4-8 nt. In case of analyzing the upstream sequences of the WSSV
ORFs at large, the occurrence of a specific motif per individual sequence was set at zero to one, but the motif had to occur in at least 60 upstream regions. In case of analyzing upstream sequences of WSSV genes belonging to the early or late kinetic clusters, the frequency of a specific motif per individual sequence was set at one. The 5' noncoding regions were categorized according to class of expression [16]: Early (ORF2, ORF8, ORF9, ORF11, ORF12, ORF15, ORF16, ORF23, ORF24, ORF25, ORF29, ORF37, ORF49, ORF53, ORF55, ORF56, ORF58, ORF60, ORF61, ORF66, ORF67, ORF69, ORF70, ORF74, ORF81, ORF85, ORF89, ORF91, ORF92, ORF93, ORF98, ORF99, ORF101, ORF103, ORF107, ORF111, ORF112, ORF115, ORF116, ORF117, ORF125, ORF126, ORF127, ORF131, ORF132, ORF142, ORF145, ORF146, ORF147, ORF152, ORF156, ORF159, ORF160, ORF161, ORF164, ORF165, ORF169, ORF170, ORF171, ORF172, ORF173, ORF177, ORF178, ORF179) and Late (ORF1, ORF3, ORF4, ORF7, ORF10, ORF14, ORF27, ORF28, ORF30, ORF31, ORF32, ORF33, ORF34, ORF35, ORF36, ORF38, ORF39, ORF41, ORF43, ORF44, ORF54, ORF57, ORF65, ORF72, ORF73, ORF75, ORF76, ORF77, ORF79, ORF80, ORF84, ORF90, ORF94, ORF95, ORF100, ORF109, ORF113, ORF114, ORF118, ORF119, ORF120, ORF121, ORF128, ORF129, ORF130, ORF134, ORF135, ORF136, ORF143, ORF148, ORF151, ORF153, ORF157, ORF167, ORF168, ORF182, ORF183, ORF184).

\section{Authors' contributions}

HM participated in the design of the computer scripts for the enumeration method and performed most of the analyses in which the scripts were used, performed the MEME analyses, the virus infections, the 5' and 3' RACE experiments including sequencing, and wrote/revised the manuscript. XYR and HS designed and programmed the computer scripts mentioned above. MCWvH and JMV conceived of the study, participated in its design and coordination and helped to draft the manuscript. All authors read and approved the final manuscript.

\section{Acknowledgements}

This work was supported by Intervet International BV, Boxmeer, The Netherlands. We thank Professor Dr Rob Goldbach for continuous interest and advice.

\section{References}

I. Lightner DV: A handbook of pathology and diagnostic procedures for diseases of penaeid shrimp. In Special publication of the World Aquaculture Society LA: Baton Rouge; 1996.

2. Vlak JM, Bonami JR, Flegel TW, Kou GH, Lightner DV, Lo CF, Loh PC, Walker PW: Nimaviridae. VIllth Report of the International Committee on Taxonomy of Viruses Elsevier 2005: 187-1 92.

3. Lo CF, Ho CH, Chen CH, Liu KF, Chiu YL, Yeh PY, Peng SE, Hsu HC, Liu HC, Chang CF, Su MS, Wang CH, Kou GH: Detection and tissue tropism of white spot syndrome baculovirus (WSBV) in captured brooders of Penaeus monodon with a special emphasis on reproductive organs. Dis Aquat Org 1997, 30:53-72.

4. Momoyama K, Hiraoka M, Nakano H, Koube H, Inouye K, Oseka N: Mass mortalities of cultured kuruma shrimp Penaeus Japoni- 
cus, in Japan in 1993: histopathological study. Fish Path 1994, 29:14|-148.

5. Wongteerasupaya C, Vickers JE, Sriurairatana S, Nash GL, Akarajamorn A, Boonsaeng V, Panyim S, Tassanakajon A, Withyachumnarnkul B, Flegel TW: A non-occluded, systemic baculovirus that occurs in cells of ectodermal and mesodermal origin and causes high mortality in the black tiger prawn Penaeus monodon. Dis Aquat Org 1995, 21:69-77.

6. Wang YG, Hassan MD, Shariff M, Zamri SM, Chen X: Histopathology and cytopathology of white spot syndrome virus (WSSV) in cultured Penaeus monodon from peninsular Malaysia with emphasis on pathogenesis and the mechanism of white spot formation. Dis Aquat Org 1999, 39:1-II.

7. Wang CH, Lo CF, Leu JH, Chou CM, Yeh PY, Chou HY, Tung MC, Chang CF, Su MS, Kou GH: Purification and genomic analysis of baculovirus associated with white spot syndrome (WSBV) of Penaeus monodon. Dis Aquat Org 1995, 23:239-242.

8. Durand S, Lightner DV, Redman RM, Bonami JR: Ultrastructure and morphogenesis of white spot syndrome baculovirus (WSSV). Dis Aquat Org 1997, 29:205-2II.

9. Marks H, Goldbach RW, Vlak JM, van Hulten MCW: Genetic variation among isolates of white spot syndrome virus. Arch Virol 2004, 149:673-697.

10. van Hulten MCW, Witteveldt J, Peters S, Kloosterboer N, Tarchini R, Fiers M, Sandbrink H, Klein Lankhorst R, Vlak JM: The white spot syndrome virus DNA genome sequence. Virology 200I, 286:7-22.

II. Yang F, He J, Lin XH, Li Q, Pan D, Zhang XB, Xu X: Complete genome sequence of the shrimp white spot bacilliform virus. jVirol 200I, 75: II8II-II820.

12. Huang C, Zhang X, Lin Q, Xu X, Hu ZH, Hew CL: Proteomic analysis of shrimp white spot syndrome viral proteins and characterization of a novel envelope protein VP466. Mol Cell Proteomics 2002, I:223-23I.

13. Tsai JM, Wang HC, Leu JH, Hsiao HH, Wang AH, Kou GH, Lo CF: Genomic and proteomic analysis of thirty-nine structural proteins of shrimp white spot syndrome virus. J Virol 2004, 78: I1360-11370.

14. van Hulten MCW, Goldbach RW, Vlak JM: Three functionally diverged major structural proteins of white spot syndrome virus evolved by gene duplication. J Gen Virol 2000, $81: 2525-2529$.

15. van Hulten MCW, Westenberg M, Goodall SD, Vlak JM: Identification of two major virion protein genes of White Spot Syndrome virus of shrimp. Virology 2000, 266:227-236.

16. Marks $\mathrm{H}$, Vorst $\mathrm{O}$, van Houwelingen AM, van Hulten MCW, Vlak JM: Gene-expression profiling of White spot syndrome virus in vivo. J Gen Virol 2005, 86:208I-2I00.

17. Liu W], Chang YS, Wang CH, Kou GH, Lo CF: Microarray and RTPCR screening for white spot syndrome virus immediateearly genes in cycloheximide-treated shrimp. Virology 2005 334:327-341.

18. Broyles SS: Vaccinia virus transcription. J Gen Virol 2003, 84:2293-2303.

19. Friesen PD: Regulation of baculovirus early gene expression. In The Baculoviruses Edited by: Miller LK. New York: Plenum Press; 1997:141-170

20. Garcia-Escudero R, Viñuela E: Structure of African swine fever virus late promoters: requirement of a TATA sequence at the initiation region. J Virol 2000, 74:8I76-8I82.

21. Rajcani J, Andrea V, Ingeborg R: Peculiarities of herpes simplex virus (HSV) transcription: an overview. Virus Genes 2004 28:293-3I0.

22. Wagner EK, Guzowski JF, Singh J: Transcription of the herpes simplex virus genome during productive and latent infection. Prog Nucleic Acid Res Mol Biol 1995, 51:123-165.

23. Lu A, Miller LD: Regulation of baculovirus late and very late gene expression. In The Baculoviruses Edited by: Miller LK. New York: Plenum Press; 1997:193-216.

24. Mistretta TA, Guarino LA: Transcriptional activity of baculovirus very late factor $I$. J Virol 2005, 79:1958-1960.

25. Pena L, Yanez RJ, Revilla Y, Vinuela E, Salas ML: African swine fever virus guanylyltransferase. Virology 1993, 193:319-328.

26. Ayres MD, Howard SC, Kuzio J, Lopez FM, Possee RD: The complete DNA sequence of Autographa californica nuclear polyhedrosis virus. Virology 1994, 202:586-605.
27. Bailey TL, Elkan C: Fitting a mixture model by expectation maximization to discover motifs in biopolymers. Proc Int Conf Intell Syst Mol Biol 1994, 2:28-36.

28. Blissard GW, Rohrmann GF: Location, sequence, transcriptional mapping, and temporal expression of the gp64 envelope glycoprotein gene of the Orgyia pseudotsugata multicapsid nuclear polyhedrosis virus. Virology 1989, 170:537-555.

29. Kim DB, Zabierowski S, DeLuca NA: The initiator element in a herpes simplex virus type I late-gene promoter enhances activation by ICP4, resulting in abundant late-gene expression. J Virol 2002, 76:1548-1558

30. Almazan F, Rodriguez JM, Andres G, Perez R, Vinuela E, Rodriguez JF: Transcriptional analysis of multigene family 110 of African swine fever virus. J Virol 1992, 66:6655-6667.

31. Marks H, Mennens M, Vlak JM, van Hulten MCW: Transcriptional analysis of the white spot syndrome virus major virion protein genes. J Gen Virol 2003, 84: I5I7-1523.

32. Birnstiel ML, Busslinger M, Strub K: Transcription termination and 3' processing: the end is in site! Cell 1985, 41:349-359.

33. Hossain MS, Khadijah S, Kwang J: Characterization of ORF89 - a latency-related gene of white spot syndrome virus. Virology 2004, 325:106-115

34. Khadijah S, Neo SY, Hossain MS, Miller LD, Mathavan S, Kwang J: Identification of white spot syndrome virus latency-related genes in specific-pathogen-free shrimps by use of a microarray. J Virol 2003, 77:10162-10167.

35. Smale ST, Kadonaga JT: The RNA polymerase II core promoter. Annu Rev Biochem 2003, 72:449-479.

36. Arnosti DN: Design and function of transcriptional switches in Drosophila. Insect Biochem Mol Biol 2002, 32: I 257-1273.

37. Cherbas L, Cherbas P: The arthropod initiator: the capsite consensus plays an important role in transcription. Insect Biochem Mol Biol 1993, 23:81-90

38. Hultmark D, Klemenz R, Gehring WJ: Translational and transcriptional control elements in the untranslated leader of the heat-shock gene hsp22. Cell 1986, 44:429-438.

39. Leu JH, Tsai JM, Wang HC, Wang AH, Wang CH, Kou GH, Lo CF: The unique stacked rings in the nucleocapsid of the white spot syndrome virus virion are formed by the major structural protein VP664, the largest viral structural protein ever found. J Virol 2005, 79: I 40-149.

40. Li Q, Chen $\mathrm{Y}$, Yang F: Identification of a collagen-like protein gene from white spot syndrome virus. Arch Virol 2004, 149:215-223.

4l. Fitzgerald M, Shenk T: The sequence 5'-AAUAAA-3' forms parts of the recognition site for polyadenylation of late SV40 mRNAs. Cell I98I, 24:25I-260.

42. Liu $X$, Yang F: Identification and function of a shrimp white spot syndrome virus (WSSV) gene that encodes a dUTPase. Virus Res 2005, I I 0:21-30.

43. Sheets MD, Ogg SC, Wickens MP: Point mutations in AAUAAA and the poly (A) addition site: effects on the accuracy and efficiency of cleavage and polyadenylation in vitro. Nucleic Acids Res 1990, 18:5799-5805.

44. Brazma A, Jonassen I, Vilo J, Ukkonen E: Predicting gene regulatory elements in silico on a genomic scale. Genome Research 1998, 8: $1202-1215$

45. Lu L, Wang H, Manopo I, Yu L, Kwang J: Baculovirus-mediated promoter assay and transcriptional analysis of white spot syndrome virus orf427 gene. Virol J 2005, 2:

46. Soderhall I, Kim YA, Jiravanichpaisal P, Lee SY, Soderhall K: An ancient role for a prokineticin domain in invertebrate hematopoiesis. J Immunol 2005, I 74:6153-6I60.

47. Chen LL, Wang HC, Huang CJ, Peng SE, Chen YG, Lin SJ, Chen WY, Dai CF, Yu HT, Wang CH, Lo CF, Kou GH: Transcriptional analysis of the DNA polymerase gene of shrimp white spot syndrome virus. Virology 2002, 301:136-147.

48. Li Q, Pan D, Zhang JH, Yang F: Identification of the thymidylate synthase within the genome of white spot syndrome virus. Gen Virol 2004, 85:2035-2044.

49. Nicholas KB, Nicholas HBJ, Deerfield DWI: GeneDoc: Analysis and Visualization of Genetic Variation. EMBNEW NEWS 1997 , 4:

50. Perl.com: The Source for Perl - perl development, perl conferences [http://www.perl.com]

5I. MEME - Introduction [http://meme.sdsc.edu/meme/intro.html] 
52. Liu WJ, Yu HT, Peng SE, Chang YS, Pien HW, Lin C], Huang CJ, Tsai MF, Huang CJ, Wang CH, Lin JY, Lo CF, Kou GH: Cloning, characterization, and phylogenetic analysis of a shrimp white spot syndrome virus gene that encodes a protein kinase. Virology 200I, 289:362-377.

53. Tsai MF, Lo CF, van Hulten MCW, Tzeng HF, Chou CM, Huang CJ Wang $\mathrm{CH}$, Lin JY, Vlak JM, Kou GH: Transcriptional analysis of the ribonucleotide reductase genes of shrimp white spot syndrome virus. Virology 2000, 277:92-99.

54. Li L, Lin S, Yanga F: Functional identification of the non-specific nuclease from white spot syndrome virus. Virology 2005, 337:399-406.

Publish with Bio Med Central and every scientist can read your work free of charge

"BioMed Central will be the most significant development for disseminating the results of biomedical research in our lifetime. "

Sir Paul Nurse, Cancer Research UK

Your research papers will be:

- available free of charge to the entire biomedical community

- peer reviewed and published immediately upon acceptance

- cited in PubMed and archived on PubMed Central

- yours - you keep the copyright

Submit your manuscript here:

http://www.biomedcentral.com/info/publishing_adv.asp
BioMedcentral 